\title{
Imaging in urinary tract infection
}

\author{
F V Gleeson, I Gordon
}

\begin{abstract}
The relationship of vesicoureteric reflex (VUR) and renal scarring was studied in 94 children (188 kidneys) with proved urinary tract infection in a district general hospital. There were 61 girls and 33 boys, with nine girls and 17 boys aged less than 1 year, 31 girls and nine boys aged between 1 and 5 years, the remaining 28 children were over 5 years of age. All children had a micturating cystourethrogram and a ${ }^{99 m}$ Tc (technetium) dimercaptosuccinic acid (DMSA) scan. Forty two of the 188 kidneys were scarred and 70 of the kidneys had VUR. Only $37 \cdot 1 \%$ of the kidneys with reflux were scarred but $61.9 \%$ of the scarred kidneys had VUR. In children of less than 1 year, $48 \%$ of kidneys with VUR were scarred whereas $70.6 \%$ of scarred kidneys had reflux. In children between 1 and 5 years of age only $36.4 \%$ of kidneys with VUR were scarred but $63.2 \%$ of scarred kidneys had VUR.

There is good correlation between the detection of a scarred kidney on DMSA and the presence of vesicoureteric reflux. However the detection of reflux particularly in children over 1 year of age shows poor correlation with renal scarring. This suggests that the primary imaging in children over 1 year of age presenting with a urinary tract infection should be of the kidney: a cystogram should be performed only if the DMSA scan is abnormal.
\end{abstract}

Urinary tract infection is common in childhood with a reported incidence of $1 \cdot 7 / 1000$ boys at risk/year and $3 \cdot 1 / 1000$ girls. ${ }^{1}$ This incidence is reversed in boys and girls under 1 year of age. Reflux nephropathy, renal damage caused by vesicoureteric reflux (VUR) plus infection, is a significant cause of end stage renal failure in young adults. It has been estimated that the risk of renal failure due to reflux nephropathy in children presenting with urinary tract infection is slightly less than $1 \%$ for boys and less than $0.5 \%$ for girls. ${ }^{2}$ Hypertension is the other major complication seen in up to $13 \%$ of patients with a history of reflux nephropathy. ${ }^{3}$ An increased incidence of toxaemia of pregnancy has also been reported. ${ }^{3}$ Despite the high morbidity of reflux nephropathy and the relative frequency of urinary tract infection in childhood there remains considerable controversy over how best to investigate these children. ${ }^{4} 5$ The age of the child when the infection occurs and its association with VUR seem the most critical factors. The kidneys of young children, less than 1 year old, are the most vulnerable, but children over 5 years seem safe, with new scars unlikely to develop. ${ }^{6}$ The main debate is on the children between these two ages, those aged 1 to 5 years. In this study the relationship of the scarred kidney to VUR and VUR to the scarred kidney are assessed in these three age groups.

\section{Patients and methods}

Children presenting to Queen Elizabeth Children's Hospital, Hackney, London (QEH) with their first episode of proved urinary tract infection between September 1985 and June 1990 were selected for study. Only those children with a structurally normal renal tract were included. Additional children with neurological and skeletal abnormalities were excluded from the study.

All children underwent a micturating cystourethrogram, to assess reflux, at $\mathrm{QEH}$ and a ${ }^{99 \mathrm{~m}} \mathrm{Tc}$ (technetium) dimercaptosuccinic acid (DMSA) renal scan, to detect renal scarring, at the Hospital for Sick Children, Great Ormond Street. The DMSA scans were performed a minimum of four weeks after the micturating cystourethrogram. Images were obtained in the posterior and both posterior oblique projections four hours after the intravenous injection of 100 $\mathrm{MBq} / 70 \mathrm{~kg}$ with the child lying directly on the gamma camera. The results of both the micturating cystourethrogram and the DMSA scan were recorded from the patient's radiography folder.

\section{Results}

Ninety four children with 188 kidneys were eligible for analysis (tables 1 and 2). There were $42(22 \cdot 3 \%)$ scarred kidneys and $70(37 \cdot 2 \%)$ kidneys were associated with VUR. The incidence of VUR was highest in the youngest age group (48.6\%), falling to $21.4 \%$ in those children

Table 1 Children grouped by age and sex

\begin{tabular}{lccl}
\hline Age (years) & Girls & Boys & Total \\
\hline$<1$ & 9 & 17 & 26 \\
$1-5$ & 31 & 9 & 40 \\
$>5$ & 21 & 7 & 28 \\
All ages & 61 & 33 & 94 \\
\hline
\end{tabular}

Table 2 The relationship of reflux and scarring in children

\begin{tabular}{llll}
\hline & Girls & Boys & Total \\
\hline Scarring detected & 20 & 15 & 35 \\
Reflux detected & 29 & 21 & 50
\end{tabular}


Table 3 The relationship of reflux to scarring

\begin{tabular}{llll}
\hline & $\begin{array}{l}\text { No of kidneys } \\
\text { with VUR }\end{array}$ & \multicolumn{2}{l}{ DMSA scan } \\
\cline { 3 - 4 } & & Scarred & Normal \\
\hline All children: & 70 & 26 & 44 \\
Boys & 30 & 10 & 20 \\
$\quad$ Girls & 40 & 16 & 24 \\
Age (years): & & 12 & 13 \\
$<1$ & 25 & 12 & 21 \\
$1-5$ & 33 & 2 & 10 \\
$>5$ & 12 & & \\
\hline
\end{tabular}

Table 4 The relationship of scarring to reflux

\begin{tabular}{clll}
\hline & $\begin{array}{l}\text { No of kidneys } \\
\text { with scarring }\end{array}$ & \multicolumn{2}{c}{ Micturating cystourethrogram } \\
\cline { 3 - 4 } & & With reflux & Without reflux \\
\hline All children: & 42 & 26 & 6 \\
Boys & 17 & 10 & 7 \\
Girls & 25 & 16 & 9 \\
Age (years): & & 12 & 5 \\
$<1$ & 17 & 12 & 7 \\
$1-5$ & 19 & 2 & 4 \\
$>5$ & 6 & & \\
\hline
\end{tabular}

over 5 years of age in keeping with the natural history of reflux. Only $37 \cdot 1 \%$ of the kidneys associated with reflux were scarred if all ages are considered. In children under 1 year of age this increased to $48.0 \%$ but fell to $36.4 \%$ in those aged between 1 and 5 years. Only $16.7 \%$ of kidneys associated with VUR in those over 5 years were scarred (table 3 ).

Renal scars were detected in $42(22 \cdot 3 \%)$ of the 188 kidneys studied. Of all the scarred kidneys, VUR was seen in $26(61.9 \%)$. In children less than 1 year of age with renal scarring VUR was seen in $70.6 \%$. In children aged between 1 and 5 years with renal scarring, VUR was seen in $63 \cdot 2 \%$ (table 4 ).

The prevalence of both VUR and renal scarring declined with increasing age.

\section{Discussion}

The long term morbidity associated with reflux nephropathy is due to the presence of renal scarring. This requires clinicians both to attempt to prevent it and to identify those children already affected at presentation. The majority of children with reflux nephropathy are noted to have scarred kidneys at the time of investigation of their initial urinary tract infection. ${ }^{6}$ Longitudinal studies have mostly failed to demonstrate the development of renal scars not present on first investigation in children followed up for urinary tract infection. ${ }^{7}$ The Birmingham Reflux Trial confirmed that although it is possible to stop reflux with surgery, there is no apparent advantage regarding renal scarring, breakthrough infection, or renal function when compared with non-operative treatment, thereby casting doubt on the benefit of its detection. ${ }^{6}$
Renal scars may be detected by intravenous urography, ultrasound, or DMSA isotope scans. Ultrasound is the least and DMSA the most sensitive technique. ${ }^{8-10}$ DMSA may in fact be over sensitive if performed within four weeks of the urinary tract infection, detecting transient areas of abnormality that may not develop into scars on long term follow up. ${ }^{9}$ Intravenous urography is difficult to perform in young children and has been shown to be insensitive when compared with DMSA scans particularly in children aged less than 6 years. ${ }^{9}$

This study confirms previous reports of the incidence of VUR in children presenting for investigation of a urinary tract infection. ${ }^{11}$ The high incidence of scarring $(48 \%)$ associated with reflux in the children under 1 year of age supports the argument that the young child, less than 1 year old, is the most susceptible to reflux nephropathy. Both clinicians and radiologists feel that this age group should undergo both cystography and DMSA investigations at presentation.

However in children over 1 year of age VUR not associated with scarring is seen in $65 \%$ of cases, thus a kidney associated with reflux in this age group is more likely to be normal than scarred. If the initial imaging is directed at the kidney in the child over 1 year of age then $56 \%$ of scarred kidneys were shown to have VUR. If this policy is assessed in those aged 1 to 5 years this then increases to $63 \%$.

We believe that renal scars detected by a DMSA scan are a good predictor of reflux in the child over 1 year of age. VUR in the older child should not be regarded as the 'villain of the piece' rather interest should be focused on the kidney which if scarred would direct the clinician to exclude VUR.

1 Dickinson JA. Incidence and outcome of symptomatic urinary tract infection in children. $B M \mathcal{F} 1979 ; \mathrm{i}: 1330-2$.

Haycock GB. Investigation of urinary tract infection. Arch Dis Child 1986;61:1155-8.

3 Jacobson SH, Eklof O, Eriksson CG, Lins L-E, Tidgren B, Winberg J. Development of hypertension and uraemia after pyelonephritis in childhood: 27 year follow up. $B M \mathcal{F}$ 989;299:703-6.

4 Cavanagh PM, Sherwood T. Too many cystograms in the investigation of urinary tract infection in children? $\mathrm{Br} \mathcal{F}$ Urol 1983;55:217-9.

5 Gordon I. Urinary tract infection in paediatrics: the role of diagnostic imaging. Br $\mathcal{F}$ Radiol 1990;63:507-11.

6 Birmingham Reflux Study Group. Prospective trial of operative versus non-operative treatment of severe vesicoureteric reflux in children: two years' observation. BMF 1983;287 $171-4$.

7 Smellie J, Edwards D, Hunter N, Normand ICS, Prescod N. Vesicoureteric reflux and renal scarring. Kidney Int 1975; Suppl 4:S65-72.

8 Verber IG, Strudley MR, Meller ST. ${ }^{99 \mathrm{~m}} \mathrm{Tc}$ dimercaptosuccinic acid scan as first investigation of urinary tract succinic acid scan as first investigation
infection. Arch Dis Child 1988;63:1320-5.

9 Goldraich NP, Ramos OL, Goldraich IH. Urography versus DMSA scan in children with vesicoureteric reflux. Pediatr DMSA scan in child

10 Stoller ML, Kogan BA. Sensitivity of ${ }^{99 \mathrm{~m}}$ technetiumdimercaptosuccinic acid for the diagnosis of chronic pyelonephritis: clinical and theoretical considerations. $\mathcal{J}$ Urol 1986;135:977-80

11 Blickman JG, Taylor GA, Lebowitz RL. Voiding cystourethrography: the initial radiological study in children with urinary tract infection. Radiology 1985;156:659-62. 